Jpn J Human Genet 39, 275-288, 1994

\title{
Annotation
}

\section{GENETIC SERVICES IN THE UNITED STATES*}

\author{
Harold CHEN and Wladimir WeRTELECKI \\ Department of Medical Genetics, University of South Alabama, \\ Mobile, Alabama 36688, USA
}

\begin{abstract}
Summary Advances in medical genetics, including mapping of human genome, improved therapy for genetic disorders, and new screening tests for carrier detection and prenatal diagnosis, have created a growing demand for clinical genetic services in the United States. Such services (diagnosis, management, and genetic counseling) received support from state, federal, and private sources and were mostly based in academic medical centers. Gradually, such programs evolved into regional or state-wide activities with an emphasis on outreach clinics. Now, an increasing number of for-profit corporations have entered into this field. Clinical genetic teams usually include clinical geneticists and other professionals with expertise in the diagnosis and management of genetic conditions and skills in information presentation and family support. The American Board of Medical Genetics, the newest member of the American Board of Medical Specialties, provides certification for five categories of genetics professionals and sets standards for training programs.

Based on personal experiences from the states of Alabama and Ohio and data from the Council of Regional Networks for Genetic Services, we show and compare trends of newborn screening programs and regional genetic services. The effects of economic and social trends as they impinge on genetic services are monitored via several databases in our center.

Key Words genetic services in the United States, Council of Regional Networks for Genetic Services (CORN), genetic training programs and certifications, newborn screening, Alabama regional genetic program
\end{abstract}

Received and accepted for publication February 14, 1994.

* This paper was presented as a Symposium on "Current Status and Future Perspectives of Genetic Services" at the 38th Annual Meeting of the Japanese Human Genetics Society in Tokyo, Japan, October 21st, 1993. 


\section{Introdution}

Advances in genetics, including mapping of human genome, improved therapy for genetic disorders, recognition of the role of genetic factors in common adulthood diseases, and new screening tests for carrier detection and presymptomatic diagnosis, create an increased demand for and awareness of clinical genetic services (Bernhardt and Pyeritz, 1992). These services, focusing on diagnosis, management, and genetic counseling, had been supported by a variety of state, provincial, federal, and foundation grants. As clinical genetics has evolved from a service with roots in research provided solely at academic medical centers to a service widely available in the community, these services in the U.S. are increasingly provided on a fee-for-service basis in various settings, including private hospitals, state-supported outreach clinics, and free-standing genetic centers.

\section{Historical Background}

The first organized institution in the United States for the study of human heredity and for giving advice to families was the Eugenics Record Office (Dice, 1952). This Office was established in 1910 at Cold Spring Harbor, New York, under the directorship of Charles B. Davenport (McDowell, 1946). Its support came from an endowment given by Mrs. E. H. Harriman. The Eugenics Record Office in 1918 became a part of the Carnegie Institution of Washington. Its studies of human heredity were later abandoned. The accumulated records of the Office were, in 1948, transferred to the Dight Institute of the University of Minnesota. After the Eugenics Record Office became inactive, human heredity was largely neglected in North America as a subject for research, although articles dealing with the heredity of particular characters continued to be published from time to time.

H. H. Newman of the University of Chicago was one of those individuals who, in this period, made active contributions to human heredity. His study of twins opened an important new field of research. Much credit for the recent revival of interest in human heredity in North America must go to Laurence H. Snyder who promoted teaching and research in human genetics. The gratifying increase of interest in this field was further influenced by the American Society of Human Genetics (founded in 1949) (Neel, 1974) and of its Journal (Epstein, 1993).

Heredity Clinic of the University of Michigan was initiated in 1940 under a research grant from the Board of Governors of the Horace H. Rackham School of Graduate Studies, where the senior author received his genetics training in the mid 1960's. James V. Neel had been the Director of the Clinic since May, 1946 until recently. Among the early heredity clinics were Dight Institute of the University of Minnesota (established in 1941), Bowman Gray School of Medicine, Winston-Salem, North Carolina (influenced considerably by late Dr. William Allan, whose awards have been given to distinguished geneticists annually by the American 
Human Genetics Society), University of Utah Laboratory of Human Genetics, University of Texas, and University of Oklahoma. Johns Hopkins Medical Genetic Clinic began in 1957.

Since 1956, human genetics has become "medicalized, subspecialized, molecularized, commercialized, and consumerized" (McKusick, 1992). While human genetics deals with biologic variation in the human, medical genetics deals with human biological variation as related to health and diseases. Medical genetics has become "professionalized" through the development of clinical colleges and certifying organizations. Clinical genetics becomes an integral part of medical genetics concerned with disorders not only in individual patients but also their families by diagnosis, prevention, and management of genetic disorders (McKusick, 1993).

\section{Genetic Services Providers}

Most comprehensive genetics centers are located in large medical centers in urban settings and are often divisions within departments of pediatric, obstetric and gynecology, or medicine (Bernhardt and Pyeritz, 1992). Free standing departments of medical genetics such as ours are rare. Some centers or state genetics programs have established outreach clinics so that a larger segment of the population could have access to genetic services. Only the largest health maintenance organizations (e.g., Kaiser/Permanente in many locations) support their own genetics services. Private genetics services have been established in some areas and offer a limited number of services, such as cytogenetics, prenatal diagnostic procedures, or DNA analysis, or in a few instances, comprehensive services, including proband evaluation. Selected specialty hospitals that provide services for patients with certain types of disorders, such as orthopedic or carniofacial anomalies, may have a clinical geneticist or genetic counselor on staff.

Genetic services are usually provided by a multidisciplinary team of individuals with expertise in the diagnosis and management of genetic conditions as well as in information presentation and family support. In most clinical genetics centers, the core providers are clinical geneticists (physicians with subspecialty training in clinical genetics) and genetic counselors (professionals with graduate-degree level training in genetic counseling). Many multidisciplinary teams also include social workers and nurses who provide psychosocial support, crisis intervention, family follow-up, and referral to community resources (Alliance of Genetic Support Group, 1992).

\section{Economic of Cinical Genetic Services}

Genetic services in the United States became more widely available in the 1960's when the National Foundation-March of Dimes and other agencies began subsidizing the efforts of clinical centers in the treatment and prevention of birth defects (Myers and Prouty, 1987; Holtzman, 1983). However, during the mid-1970's, the National Foundation weaned many previously supported genetic centers of 
major financial support. By that time, genetic services had already been widely recognized as "indicated" patient evaluations and patients and their insurance companies had assumed payments for these services. In 1976, the National Genetic Disease Act perpetuated and expanded the work of the National Foundation by subsidizing the efforts of ongoing genetic centers and assisting other genetic centers for possible funding. Three distinct areas of clinical services became chargeable: laboratory services, clinical diagnostic services (consultation), and genetic counseling.

In 1981, U.S. Congress, upon the urging of president Reagan, repealed laws that had authorized funding for categorical health and welfare programs, including genetic diseases and comprehensive hemophilia services. Simultaneously, congress passed Block Grants Acts that provided funds to the States for continuing these programs at their discretion. Maternal and Child Health (MCH) Service Block Grant Act included genetic services (and sickle cell programs) and hemophilia centers. The funds available in the set-aside Special Projects of Regional and National Significance (SPRANS) were considerably less than the funds allocated for the same programs in the previous years.

Clinical genetics is a relatively new speciality (Pyeritz et al., 1987). Centers providing clinical genetic services have relied heavily on a variety of funding sources, especially federal, state, institutional, and foundation grants and subsidies from public and private sectors (Bernhardt et al., 1987, Bernhardt and Pyeritz, 1992). However, during the past few years, most clinical genetics services have been supported increasingly by direct billings of patients (Bernhardt and Pyeritz, 1989). Revision of Physician's Current Procedural Terminology (CPT) codes in 1987 had improved definition of genetic laboratory services but did not address the entire scope of cognitive genetic services. While not generating enough income to cover its own costs, clinical genetic services do bring considerable revenue to the medical center (Bernhardt et al., 1992).

Increasingly, financial support of clinical services relies on income derived from direct patient charges. Fortunately, many genetics services have remained accessible because third party payers, including Medicaid, provide reimbursement for them. However, some new services, such as DNA diagnostic testing, or services that may be provided by non-physicians, such as genetic counseling, may not be reimbursed by all third parties.

Cognitive genetic services are by nature time consuming, labor intensive, and not self-supporting. Completing an evaluation of a new family referred for genetic diagnosis and counseling has been shown to require an average of 7 hours of staff time when considering the amount of time required before, during, and after the clinic appointment. In the United States, many states have recognized the importance of genetics services and partially subsidize genetics centers with state funding, allowing for provision of some free services, sliding fee scales for indigent families, and partial salaty support for providers. The extent to which economic factors affect genetic service accessibility and utilization and the effects on genetic services of future 
changes in health care regulations and financing has not been well studied.

Recent health care reform proposal by president Clinton focused on preventive medicine and availability of medical services to all citizens. Although direct consequences to genetic services in general will not be known for some time, it is felt that genetic services will continue to be supported.

\section{Academic vs. Private}

Commercial genetic-testing companies arose because they saw a market for their services and perceived a growth industry with the potential for considerable profits. In many instances, exclusive contracts have been negotiated between a third-party payor and a specific commercial laboratory, based primarily on fee structure, then on turnaround times, followed by delivery of services, but not so much to total cells analyzed or numbers of chromosome bands (Hecht and Hecht, 1992). Potential problems for mega-commercial laboratories include (Milunsky, 1992a, b): limitation of the knowledge on the subject matter by those private physicians who rely on the laboratory providing the test results; not directly involved in patient cares; rushing to market new techniques; and using master degree genetic counselors to practice medicine with liabilities to be shared by private physicians. Practicing physicians should be educated about importance of comprehensive genetic care for their patients, whether it be in the academic or the "private" setting.

\section{American Board of Medical Genetics, American College of Medical Genetics, and Certification of Medical Geneticists}

In 1990, the American Society of Human Genetics (ASHG) Board of Directors appointed a committee to evaluate the needs for and feasibility of establishing a College or Academy to oversee the provision of genetic services nationally, to represent the providers of these services and their patients with genetic disorders and to elevate the rapidly emerging specialty of Medical Genetics to full representation within the established medical service, certification and regulatory organizations. The committee recommended the establishment of the American College of Medical Genetics (ACMG), which was then incorporated as an independent body in December, 1991 (American College of Medical Genetics, 1991).

The American Board of Medical Genetics provides certification for five categories of genetics professionals and also sets standards for genetics training programs. Physicians are certified as specialists in Medical Genetics by the American Board of Medical Genetics, a member board of the American Board of Medical Specialties (ABMS). The establishment of the American Board of Medical Genetics evolved out of a recognized need and commitment by the founding members to improve the level and standards of clinical care in the area of medical genetics. To enforce its commitment to quality care at the individual level, the Board with the assistance of the National Board of Medical Examiners, instituted certifying examinations in these areas of expertise. These certifying examinations are offered 
every three years (1981, 1984, 1987, 1990, 1993, etc.) (American Society of Human Genetics, Genetics Society of America, American Board of Medical Genetics, 1992-1993). Because the technology of medical genetics is advancing so rapidly, test questions must be thoroughly reviewed and rewritten each time to be sure that the geneticists who take the examinations are thoroughly up-to-date in a fast-moving field. In order to be eligible to sit for the examination, the candidate must have successfully completed at least a two year accredited training program and complete an application form with the appropriate documentation of didactic training and a logbook of cases.

Medical genetics programs have enjoyed steady development throughout U.S. for more than 20 years (Finley et al., 1987). Current use of DNA probes will result in an even greater need for expansion of services. Therefore, organization of more training programs will be necessary to ensure that the needed personnel will be available and adequately trained. In order to ensure that state-of-the-art techniques, standards and practices are being met at the institutional level, a stringent process of accreditation has been made available to programs that train medical genetics professionals preparing for certification in the areas of clinical and laboratory medicine. In the U.S., there are 99 accredited graduate and postgraduate training programs in human genetics (American Society of Human Genetics, 1992). In addition, there are 11 cytogenetic technology training programs available (Knutsen, 1992).

Since the Board's inception in 1979 and its incorporation in 1980, 994 M.D.'s and Ph.D's [957 from U.S.; 15 from Canada; 22 from foreign countries, including one from Japan (Dr. Jun Oizumi, a clinical geneticist at the National Children's Medical Research Center, Tokyo)] have become certified in the various specialty areas of medical genetics. Until 1991, the Board maintained itself as a separate and independent governing body with a philosophy of promoting equal importance to a variety of backgrounds in medical genetics. In December of 1991, the Board was approved for membership by the American Board of Medical Specialties with the provision that Master's level counselors would not be certified under the auspices of an ABMS approved board (Marquis Who's Who, 1994).

Areas of certification include Clinical Geneticist, Ph.D. Medical Geneticist, Clinical Cytogeneticist, Clinical Biochemical Geneticist, and Clinical Molecular Geneticist. Subject areas of the general examination include 1) Basic Genetics, 2) Biochemical Genetics, 3) Clinical Genetics, 4) Cytogenetics, 5) Immunogenetics, 6) Mathematic genetics and risk assessment, and 7) Molecular Genetics.

\section{Newborn Screening Tests Performed in U.S.A.}

In Japan, newborn screening programs are primarily for early detection and treatment but genetic counseling and family services related to screenings are not adequate. However, in the United States, newborn screening programs are not only for early detection and treatment, but also an integral part of the comprehensive 
genetic services. Genetic counseling of families and prenatal diagnosis are one of the important purpose of newborn screening programs.

In most states, there are laws mandating newborn screening programs. The most classic one is the phenylketonuria (PKU) screening. Recently, the American Bar Foundation analyzed each state's laws and regulations governing newborn screening, compared alternatives taken in different states, and underscored the wide diversity of legislative and administrative oversight (Chen, 1988). The screening tests, the number of states performing the test, and the incidence of the disease screened are given in the following table (Table 1) (Burist and Tuerck, 1992):

\section{Newborn Screenings in Ohio}

In March 1962, Ohio participated in the national field trials of a bacterial inhibition assay developed by Dr. Robert Guthrie. The State Laboratory tested 28,901 infants from 19 hospitals and detected the first five cases of phenylketonuria (PKU) during this period. In June 1965 the Ohio General Assembly enacted the Revised State Code effective July 1966 to provide for mandatory testing of all infants born in Ohio. Homocystinuria, galactosemia, and hypothyroidism were added later. By 1990, a total of 4,022,285 newborns were screened which detected 297 PKU, 10 homocystinuria, 56 galactosemia, and 214 hypothyroidism (Chen, 1992).

Hemoglobinopathies represent a major health problem in the United States and constitute the most common genetic disorder in some populations. Sickle cell anemia affects about 1 in 400 African-American newborns. In the State of Ohio, more than 2,800 residents are affected and at least 86,000 are carriers. In April 1987, the National Institutes of Health, Washington, D.C., conducted a consensus development conference which recommended early diagnosis including newborn screening and comprehensive care of hemoglobinopathies. In May 1989,

Table 1. Newborn screening tests performed by the number of States in U.S.A. and the respective incidences of the disorders.

\begin{tabular}{lcl}
\multicolumn{1}{c}{ Tests } & States & Incidence \\
\hline PKU, Hyperphenylalaninemia & 50 & $1: 12,000$ \\
Maple syrup urine disease & 23 & $1: 250,000$ \\
Homocystinuria & 22 & $1: 250,000$ \\
Tyrosinemia & 6 & $1: 150,000$ \\
Hypothyroidism & 50 & $1: 4,000$ \\
Galactosemia & 37 & $1: 60,000$ \\
Galactokinase deficiency & 17 & $1: 250,000$ \\
Biotinidase deficiency & 13 & $1: 250,000$ \\
Sickle cell diseases & 40 & $1: 400$ (African American) \\
Congenital adrenal hyperplasia & 6 & $1: 12,000$ \\
Cystic fibrosis & 3 & $1: 2,500$ (Caucasian) \\
\hline
\end{tabular}


the Ohio Advisory Council on Newborn Screening for Hemoglobinopathies was created and actual newborn screenings were carried out by June that year. By April 1992, a total of 520,832 newborns were screened which detected 4,039 AF, 6,475 FAS, 1,878 FAC, 184 FAE, 117 FAD, 152 FSS, 61 FSC, 31 FCC, 6 FS + BARTS, and 2,774 other hemoglobinopathies.

\section{Newborn Screenings in Alabama}

Alabama has been screening for PKU for 25 years, hypothyroidism for 12 years, and hemoglobinopathies for 4 years. Annually, approximately 3 PKU infants, 12-15 hypothyroid infants, 70 medically significant hemoglobins, and 1,600 carrier (trait) hemoglobins are identified (Hofer, 1993). Galactosemia and congenital adrenal hyperplasia are two new tests to be added in 1992.

Since 1988, newborn screening in Alabama and nationwide has been affected by the following trends (Hofer, 1993):

1. An increasing number of newborns discharged before 72 hours which do not meet laboratory criteria for interpretation of the tests.

2. Early discharge accounts for approximately $60 \%$ of births in Alabama $(37,000)$.

3. Guidelines for newborn screening systems were published in late 1990 by the Council of Regional Networks for Genetic Services.

4. Follow-up for hemoglobins has shown short term problems with patient's noncompliant with follow-up.

5. The possibility of genetic counseling and "prenatal" diagnosis for families that have an affected child, make follow-up counseling more important.

6. Long term follow-up not anticipated 25 years ago, is now important as demonstrated in Maternal PKU children where PKU mothers need counseling and diet management for their phenylalanine levels prior to conception and throughout pregnancy to protect their child from the effects on phenylalanine in utero.

7. Future treatment and therapies for conditions screened will make follow-up and re-contact of children important. An example is bone marrow transplant for sickle cell, inclusion of sickle cell children in stroke protocols, etc.

Current patient management makes a newborn screening system that involves the cooperation of the family, private physicians, tertiary endocrine/hematology/ genetic specialists, and the public health department necessary for optimum patient care.

\section{Council of Regional Networks for Genetic Services}

The Council of Regional Networks for Genetic Services (CORN) is a federally funded effort to improve the quantity, quality, and availability of cost effective genetic services nationwide. CORN was established in 1985 in response to the need for an organization to coordinate activities among federally funded regional genetic networks and to implement programs of national significance that emerged from regional initiatives. CORN functions to ensure open communication among 
the 10 regional networks and to encourage the development of minimum guidelines for services, laboratories, educational programs, collection of data, etc. In addition, CORN promotes the collection of data regarding genetic services in order to document the utilization of such services.

The membership of CORN includes representatives from each of the 10 regional genetic services networks, the national sickle cell disease programs, the Alliance of Genetic Support Groups, genetic service providers, public health officials, consumers, and other health care professionals. Ohio belongs to Great Lakes Regional Genetics Group (GLaRGG) and Alabama to Southeast Regional Genetics Group (SERGG).

The operational activities of CORN are performed by standing committees which address the identified areas of concern in the discipline of genetics. At present, these committees are: Birth Defects Surveillance, Communications/Liaison, Data and Evaluation, Education, Ethics, Finance, Newborn Screening, Quality Assurance, Sickle Cell/Thalassemia and other Hemoglobin Variants, Teratogen Information Systems. The CORN committees are designed to study, plan, evaluate, report, recommend and implement projects and programs that are priorities of CORN.

For the past four years, the Data and Evaluation Committee of the CORN has surveyed genetic service centers throughout the United States to obtain information regarding the provision of prenatal, clinical, and laboratory genetic services. This collection effort is termed the CORN Minimum Data Set (MDS) collection and is supported by the U.S. Department of Health and Human Services Maternal and Child Health Bureau. The results of this survey are published in the annual CORN Minimum Data Set Report.

\section{Cytogenetic Laboratory Services in the United States}

328 public and private cytogenetic laboratories were listed in the International Cytogenetic Laboratory Directory by Association of Cytogenetic Technology (Knutsen, 1992). 289 of those reported the numbers of procedures. The following table (Table 2) lists the number of procedures in the U.S.A. survey and compares them with that of Mobile Regional Genetic Services.

\section{Clinical DNA Diagnostic Laboratory Services in the United States}

According to CORN Survey of clinical DNA diagnostic laboratories (Corn Quality Assurance Committee DNA Testing Subcommittee, 1991), genetic disorders tested include: alpha-l-antitripsin deficiency, adenomatous polyposis coli, adult polycystic kidney disease, alpha-thalassemia, beta-thalassemia, congenital adrenal hyperplasia, cystic fibrosis, carbamylphosphate synthetase I deficiency, Duchenne/Becker muscular dystrophy, Ehlers-Danlos syndrome, familial amyloidosis, fragile X, Friedreich ataxia, Huntington disease, hemophilia A and B, Lesch Nyhan disease, myotonic dystrophy, multiple endocrine neoplasia type $I$ and 
Table 2. Comparison of the total number of procedures performed by cytogenetic laboratories in the U.S.A. survey and that performed by Mobile

Regional Genetic Services.

\begin{tabular}{lcc}
\hline Types of procedures & $\begin{array}{c}\text { No. of procedures } \\
\text { (USA) }\end{array}$ & $\begin{array}{c}\text { No. of procedures } \\
\text { (Mobile) }\end{array}$ \\
\hline Constitutional studies: & 362,138 & 1,432 \\
$\quad$ Total except fragile X & $107,220(29.6 \%)$ & $532(37.0 \%)$ \\
Peripheral blood & $1,313(0.4 \%)$ & $86(6.0 \%)$ \\
Bone marrow & $202,347(55.8 \%)$ & $707(49.3 \%)$ \\
Amniotic fluid & $24,898(6.9 \%)$ & 0 \\
Chorionic villus & $6,921(1.9 \%)$ & $34(2.3 \%)$ \\
Non-cancerous solid tissue & $19,439(5.4 \%)$ & $73(5.0 \%)$ \\
Products of conception & $26,572(+1,236)$ & $124(+22)$ \\
Fragile X & & \\
Neoplastic tissue: & 63,871 & \\
Bone marrow/Peripheral blood & 1,854 & \\
Lymph node & 3,507 & \\
Solid tumor & 410 & \\
Other (effusions, etc.) & 2,358 & \\
Continuous cell line & 6,149 & \\
Molecular techniques &
\end{tabular}

IIa, neurofibromatosis I, Norries disease, ornithine transcarbamylase deficiency, osteogenesis imperfecta, phenylketonuria, Pelizaeus-Merzbacher disease, PraderWilli syndrome, retinoblastoma, sickle cell disease, Tay-Sachs disease, WiskottAldrich disease, X-linked lymphoproliferative disease, and others. Non-genetic applications include: $B$ cell rearrangements (heavy chain), DNA banking, Bcr rearrangements, bone marrow engraftment, forensic testing, $\kappa$ or $\lambda$ chian rearrangements (light chain), oncogenes, paternity testing, $\mathrm{T}$ cell markers and $\mathrm{Y}$ probes. Rapid progress in DNA testings during last few years have been reviewed by Cooper and Schmidtke (1993).

\section{Southeastern Regional Services (SERGG)}

SERGG, one of the 10 regional genetic networks in U.S., is composed of genetic centers from 9 states: Alabama, Florida, Georgia, Kentucky, Louisiana, Mississippi, North Carolina, South Carolina, and Tennessee [Southeastern Regional Group (SERGG), 1992]. Various Genetic Programs in this region are given in the following table (Table 3).

\section{Regional Genetic Services in South Alabama}

In 1973, the Medical College of the University of South Alabama accepted 
Table 3. The total number of various genetic programs available in Southeastern Regional Genetic Services (SERGG).

\begin{tabular}{lcccc}
\hline State & $\begin{array}{c}\text { Medical } \\
\text { genetics }\end{array}$ & $\begin{array}{c}\text { Biochemical } \\
\text { genetics }\end{array}$ & $\begin{array}{c}\text { Molecular } \\
\text { genetics }\end{array}$ & $\begin{array}{c}\text { Sickle cell } \\
\text { anemia }\end{array}$ \\
\hline Alabama & 2 & 1 & 1 & 12 \\
Florida & 9 & 3 & 4 & 2 \\
Georgia & 10 & 2 & 0 & 12 \\
Kentucky & 4 & 1 & 0 & 4 \\
Louisiana & 4 & 1 & 0 & 4 \\
Mississippi & 3 & 1 & 0 & 4 \\
North Carolina & 6 & 2 & 5 & 16 \\
South Carolina & 4 & 1 & 1 & 9 \\
Tennessec & 11 & 1 & 4 & 16 \\
\hline
\end{tabular}

its first class of medical students. Two years later, a free-standing Department of Medical Genetics was organized (Wertelecki, 1979, 1991).

Alabama is a state of approximately one-third the size of Italy; its southern half, comprised of 31 counties, is the main focus of our educational programs. Our clinical and laboratory services, in addition to South Alabama, extend into the adjoining areas of Florida and Mississippi. Historically, the Gulf Coast was a cohesive part of the French and Spanish dominions and its development and character emerged from five settlements, now the coastal cities of Pensacola, Mobile, Pascagoula, Biloxi, and New Orleans. Pensacola was founded by the Spanish in 1696. Sixty miles west, in 1702, the French founded Mobile as the first capital of Louisiana, later moved to Biloxi in 1720 and to New Orleans in 1722. Subsequent incorporation have not altered a common legacy and de-facto demographic linkages. The Gulf Coast reflects noteworthy cultural and ethnic heterogeneity stemming from multiple waves of colonists and refugees, the latest from Vietnam and Cambodia.

The city of Mobile has a population of 365,000 and the Gulf Coast is relatively densely populated. Our services reach a coastal population of approximately 700,000 residing in three states. In addition, our services (university genetic clinics and six satellite clinics) and educational programs are focused on 31 South Alabama rural counties which represent approximately half of the State of Alabama (Wertelecki, 1991; Wertelecki et al., 1987). Much of South Alabama is less developed than North Alabama or the Gulf Coast.

Our educational programs include training of medical students, house staff and fellows, practicing physicians, nurses, and teachers. Since 1976, a 40-hour course has been presented to each class of approximately 64 medical students at the end of their second year curriculum. The contact hours, when compared to other medical schools, are abundant and place us as the eighth highest in the country. 
Programs for house staff and fellows rely primarily on clinical consultation and conferences. We also offer fellowships in clinical genetics and clinical cytogenetics and have provided training to ten fellows, five from abroad. Intensive clinical exercises (Mini-Residencies) are offered to practicing physicians by our staff and guest experts amalgamating advances in epidemiology, teratology, genetics and clinical medicine. Mini-Internships are provided to nurses and other health professionals by participating in a correspondence course and "hands-on" experience at our center. The last component of our educational programs is coordinated by a school teacher. Our goal is to reach teenagers, who will become future parents.

An "Information Center" was developed as a resource to provide timely and accurate information and materials to patients, families, teachers, health professionals and agencies. A computerized database (FAMFO) is used to facilitate the dissemination of information about national, regional and State support groups, fact sheets and books.

Significant effort and resources were invested to develop a series of computerized databases (Wertelecki and Superneau, 1978a, b), since educational programs are quite costly and their effectiveness needs to be documented. Over a span of a decade, our databases now reflect cumulative changes dictated by experience. Currently, there are four interactive databases. The first (GENFO) computes sociodemographic and proband-based medical activities. GENFO can generate reports for the Council of Regional Genetics Networks and other agencies. The second database (LABFO) computes cytogenetic services and other laboratory data. A third database (FAMFO) provides rapid access to fact sheets, booklets, audiovisual materials and addresses of support groups needed by patients, families, and physicians. A fourth database is used for accounting purposes.

Using the Mobile Genetic Services Codes (Wertelecki and Superneau, 1987a), prevalent diagnostic-genetic risk categories were derived from 1,418 consecutive service encounters (Wertelecki and Superneau, 1978b): The following 12 clinical categories were accounted for $45 \%$ of encounters (mental retardation (unclassified), neurofibromatosis, nervous system (dysplasia-malformation), Down syndrome, oro-facial malformations, Marfan syndrome, malformation syndromes, Turner syndrome, no evidence of abnormality, meningomyelocele, advanced maternal age, and rare autosomal chromosome disorders). The following 16 additional clinical categories were accounted for $17 \%$ of additional encounters (growth failure, deafness, fetal alcohol syndrome, osteogenesis imperfecta, fragile $X$ syndrome, trisomy 18 , trisomy 13, sickle cell anemia, Klinefelter syndrome, genital malformation, microcephaly, von Willebrand disease, Prader-Willi syndrome, hemihypertrophy, achondroplasia, and congenital heart malformatilon). Pervalent metabolic disorders encountered were albinism, phenylketonuria, mucopolysaccharidoses, galactosemia, complement deficiency, urea cycle abnormality, mucolipidoses, lactic acidosis, glycogen storage disease, adrenogenital syndrome, porphyria, Wiskott-Aldrich syndrome, hemophilia, Gaucher disease, vitiligo, Lesch-Nyhan syndrome, Wilson 
disease, carnitine deficiency, Menkes disease, and Duchenne muscular dystrophy.

Acknowledgment The authors are obliged to Dr. Yoshikazu Kuroki and Dr. Yoshimitsu Fukushima for the opportunity to present this paper at the 38th Annual Meetinng of the Japanese Human Genetics Society.

\section{REFERENCES}

Alliance of Genetic Support Group (1992): Directory of National Genetic Voluntary Organization and Related Resources. Chevy Chase, Maryland

American College of Medical Genetics (1991): Bylaws

American Society of Human Genetics (1992): 1992-93 Guide to North American Graduate and Postgraduate Training Programs in Human Genetics

American Society of Human Genetics, Genetics Society of America, American Board of Medical Genetics (1992-1993): Membership Directory

Bernhardt BA, Pyeritz RE (1989): The economics of clinical genetics services. III. Cognitive genetics services are not self-supporting. Am J Hum Genet 44: 288-293

Bernhardt BA, Pyeritz RE (1992): The organization and delivery of clinical genetics services. Pediatr Clin N Am 39: 1-12

Bernhardt BA, Weiner J, Foster EC, Tumpson JE, Pyeritz RE (1987): The economics of clinical genetics services. II. A time analysis of a medical genetics clinic. Am J Hum Genet 41 : 559565

Bernhardt BA, Tumpson JE, Pyeritz RE (1992): The economics of clinical genetics services. IV. Financial impact of outpatient genetic services on an academic institution. Am J Hum Genet 50: $84-91$

Burist NRM, Tuerck JM (1992): The practitioner's role in newborn screening. Pediatr Clin N Am 39: $199-211$

Chen H (1988): Medical Genetics Handbook. Warren H. Green, Inc., St Louis

Chen H (ed) (1992): Resource Manual for Hemoglobinopathies. An Essential Guide for Health Professionals. Advisory Council on Newborn Screening for Hemoglobinopathies, State of Ohio. U.S.A.

Cooper DN, Schmidtke J (1993): Diagnosis of human genetic disease using recombinant DNA. Hum Genet 92: 211-236

CORN Quality Assurance Committee DNA Testing Subcommittee (1991): Survey of Clinical DNA Diagnostic Labs, June

Dice LR (1952): Heredity clinics: Their value for public service and for research. Am J Hum Genet 4: $1-13$

Epstein CJ (1993): Editorial: Seven momentous years. Am J Hum Genet 53: 1163-1166

Finley WH, Finley SC, Dyer RL (Letter) (1987): Survey of medical genetics personnel. Am J Hum Genet 40: 374-377

Hecht F, Hecht BK (Letter) (1992): Descent into demonology and protectionism. Am J Hum Genet 51: $893-894$

Hofer LM (1993): Newborn Screening in Alabama-An overview. Alabama Pediatrician

Holtzman NA (1983): The impact of the federal cutback on genetic services. Am J Med Genet 15: 353-365

Knutsen T (ed) (1992): International Cytogenetic Laboratory Directory. Association of Cytogenetic Technologists, Burbank, California

Marquis Who's Who (1994): The official ABMS Directory of Board Certified Medical Geneticists. New Providence, New Jersey, Reed Reference Publishing Co, 26th ed

McDowell EC (1946): Charles Benedict Davenport, 1866-1944: a study of conflicting influences.

Vol. 39, No. 2, 1994 
Bios 17: $1-50$

McKusick VA (1992): Presidential Address, Eighth International Congress of Human Genetics: Human genetics: The last 35 years, the present, and the future. Am J Hum Genet 50: 663670

McKusick VA (1993): Medical genetics. A 40-year perspective on the evolution of a medical specialty from a basic science. JAMA 270:2351-2356

Milunsky A (1992a): Threatened survival of academic-based genetic laboratory services. Am J Hum Genet 50: 643-645

Milunsky A (Letter) (1992b): Reply to Hecht and Hecht, Trigg and Geier, and Warren. Am I Hum Genet 51: 894-895

Myers TL, Prouty LA (1987): Consumer costs for genetic services. Am J Hum Genet 26: 521-530

Neel JV (1974): Our twenty-fifth. An J Hum Genet 26: 136-144

Pyeritz RE, Tumpson JE. Bernhardt BA (1987): The economics of clinical genetics services. I. Preview. Am J Hum Genet 41: 549-558

Southeastern Regional Genetics Group (SERGG) (1992): Directory of Services, July

Wertelecki W (1979): Regional rural genetics program: Educational considerations. In: The management of genetic disorders. Proceedings of the second International Clinical Genetics Seminar on the management of Genetics Disorders, Athens, Greece, June, 1979. New York: Alan R. Liss, Inc, pp 53-65

Wertelecki W (1991): A regional genetics program in Alabama with emphasis on education and clinicians: Achievements and experience. In: Fujiki N, Bulyzhenkov, Bankowski A (eds): Medical Genetics and Society, Amsterdam/New York, Kugler Publications, pp 21-31

Wertelecki W, Superneau DW (1987a): A genetic services microcomputer data base. Part I. Design and implementation. Am J Med Sci 24: 281-289

Wertelecki W, Superneau DW (1987b): A genetic services microcomputer data base. Part II. Results and trends. Am J Med Sci 24: 397-399

Wertelecki W, Huffstutler J, Superneau D, Burns R, Hoff C (1987): Effects of education, distance and satellite clinics on the growth of genetic services. J Biosoc Sci 19: 487-493 